\title{
Total Demand, Fiscal Restraint, and Reduced Monetary Expansion
}

Total

OTAL DEMAND for goods and services showed a strong gain in the third quarter, continuing the rapid pace of the previous year. Expansion of aggregate spending outpaced gains in productive capacity, and prices increased at about a 4 per cent rate. Consumer spending rose sharply, as the tax increase had no immediate dampening effect on constmer demand. Buoyant consumer demand in the face of the increase in Federal income taxes has cast doubt in some quarters on the effectiveness of tax policy as an antiinflationary weapon. Individuals, benefiting from rapid increases in income and a relatively large stock of savings, absorbed the initial impact of the tax hike without moderating their spending.

Less stimulative monetary and fiscal actions in the recent past are expected to dampen pressures on aggregate spending in coming months, however. In addition to the burden of the income tax surcharge,

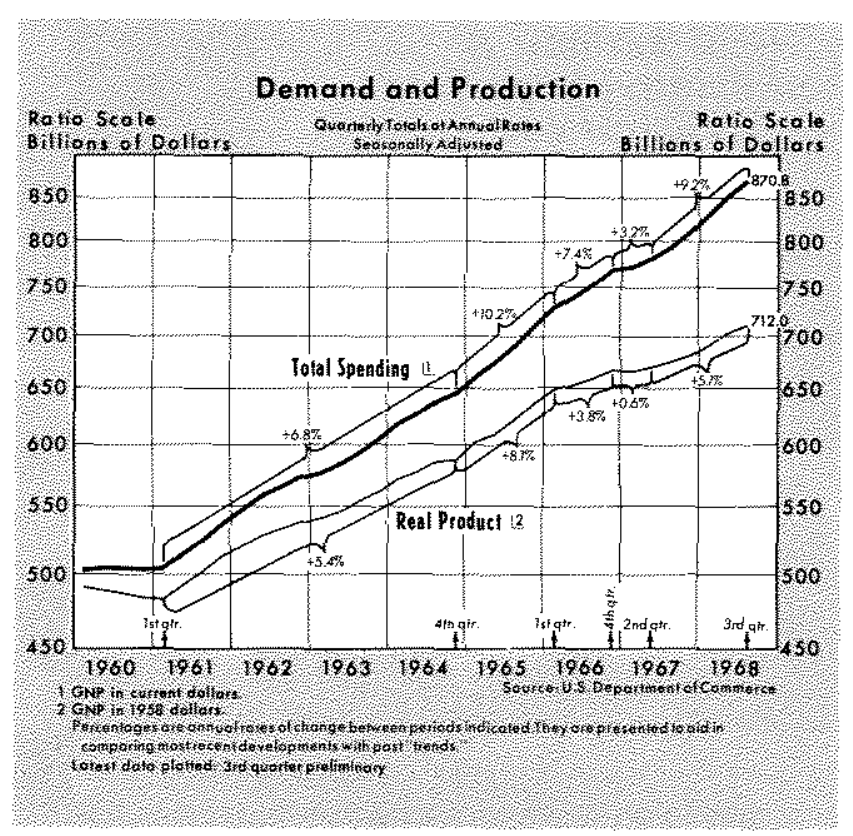

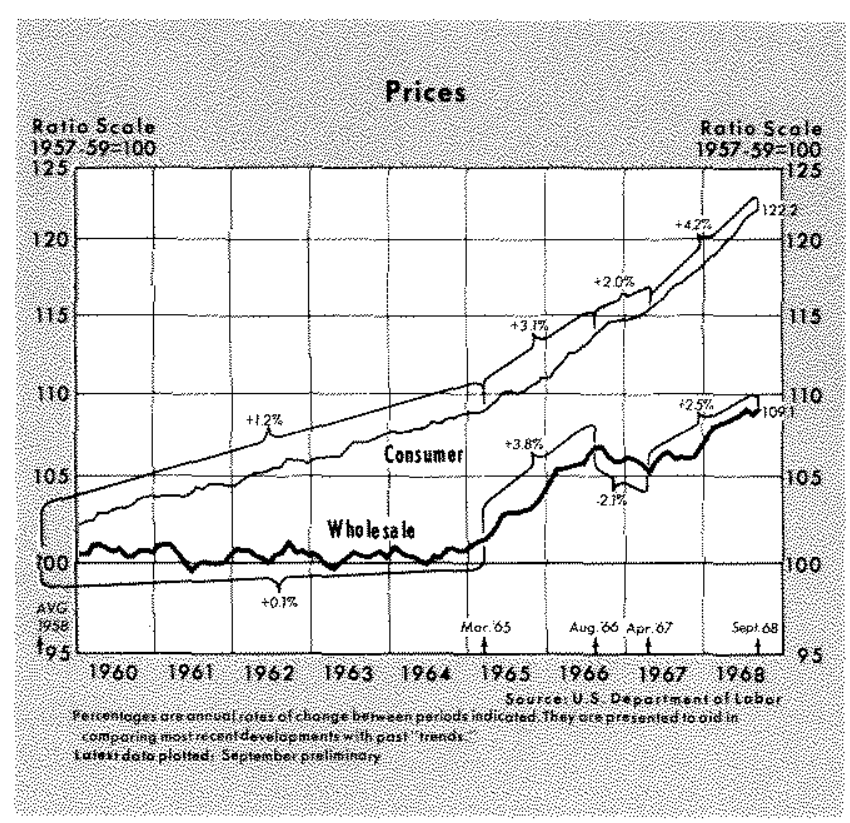

consumers will face larger social security contributions in late 1968 and early 1969. Under the provisions of the June fiscal program, Government spending, which has buoyed total demand for some time, is scheduled to slow. The rate of monetary expansion has slowed considerably since mid-year, and continuation of such a trend would tend to dampen growth of total spending.

\section{Demand and production}

Total spending increased at an 8.7 per cent annual rate in the third quarter, about the same rate as the 9.3 per cent during the previous four quarters, and substantially above the 6 per cent average rate of increase from 1957 to 1967 . Real product rose at a 5 per cent rate in the quarter, about the same as during the previous year. Prices advanced at a 3.7 per cent rate in the third quarter, not significantly 
less than during the previous year, and substantially above the 1957 to 1967 trend rate of 2 per cent.

Since the moderate slowdown in early 1967 , growth of total spending has reflected primarily expansion of final sales, i.e, spending other than for inventory. Final sales increased at a 10 per cent rate in the third quarter, slightly faster than the 8.2 per cent increase of the previous year and significantly above the average gain of 6 per cent from 1957 to 1967.

Despite the increase in personal income taxes which became effective in July, individuals increased their demand for goods and services in the third quarter. Consumer spending rose at a 10.6 per cent rate, compared with an 8 per cent increase during the previous year and a trend rate of 6 per cent from 1957 to 1967.

The 10 per cent surcharge on personal income taxes withdrew about $\$ 5.5$ billion from disposable income in the third quarter, reducing the gain to a 4.4 per cent annual rate in the third quarter from an 8.3 per cent advance in the previous year. From 1957 to 1967, disposable income increased at an average rate of 6 per cent per year. With the surcharge in effect, disposable income in coming months can be expected to advance at about the same rate as personal income.

The surcharge is intended to dampen consumer spending by slowing growth of take-home pay. Individuals offset this effect, however, by sharply reducing their rate of saving and by making increased use of credit. Individuals saved an average 7.3 per cent of their income from late 1966 to mid-1968,

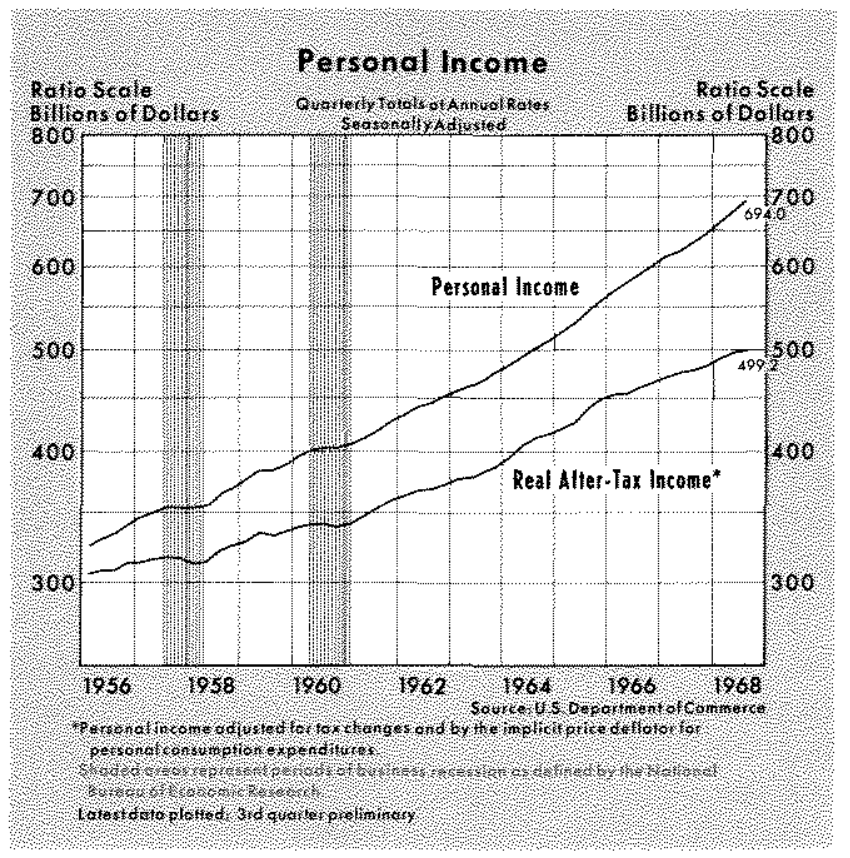

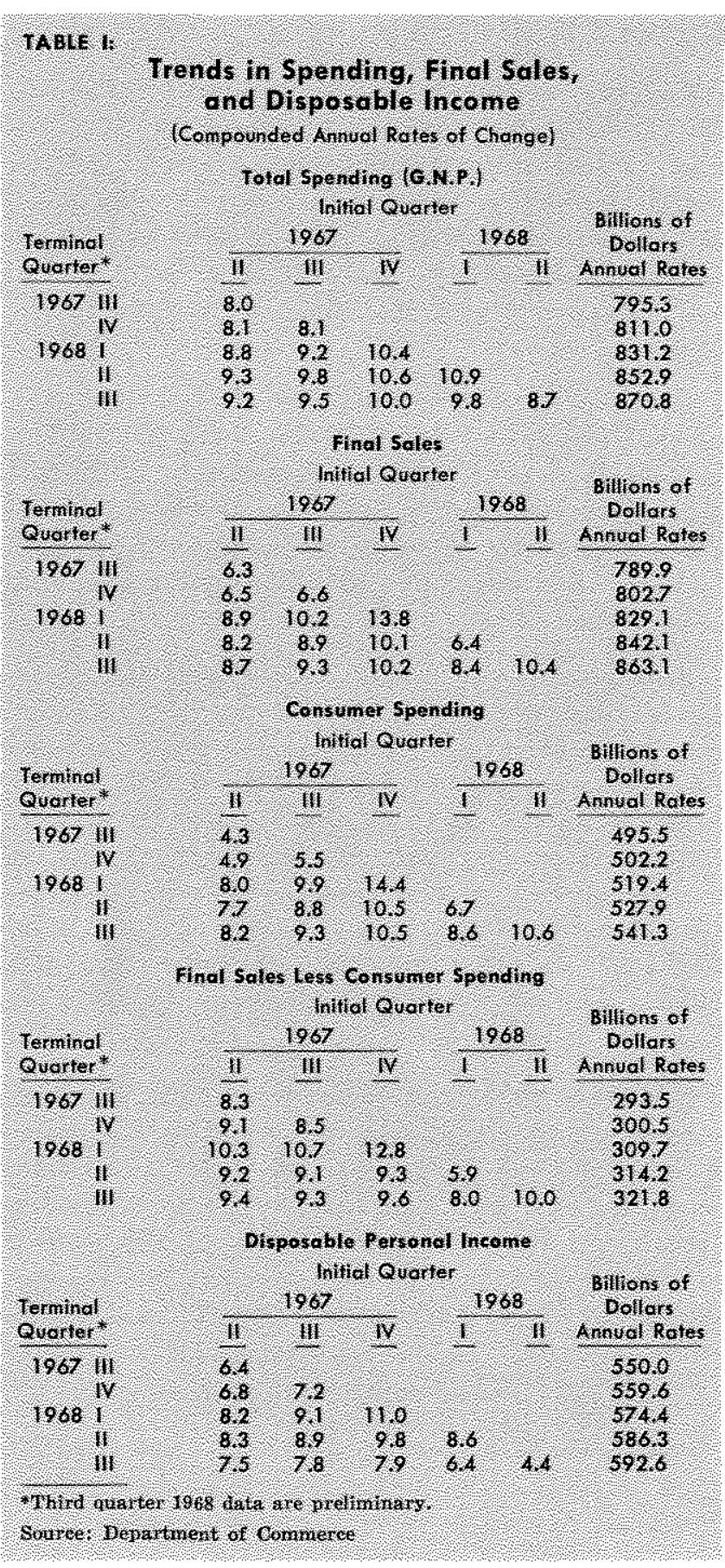

compared with an average of 6 per cent over the previous decade. More than half of the third quarter increase in consumer spending reflected the shift from saving to spending, as the saving rate fell to about 6 per cent. By maintaining an average rate of saving at 6 per cent of take-home pay during the year that the surcharge is scheduled to be in effect, individuals could meet about $\$ 7$ billion of tax liabilities with little or no effect on spending. The surcharge is currently estimated to increase personal income taxes by $\$ 7.8$ billion during fiscal 1969 . 


\section{Recen Fiscal Actions}

Federal spending increased 12 per cent in the year ending in the third quarter, compared with a 15 per cent rate of increase from 1965 to 1967. Defense spending rose 9 per cent in the last year, after rising at a 20 per cent rate from 1965 to 1967 . Nondefense spending advanced 14 per cent from third quarter 1967, compared with the 1965-1967 rate of 12 per cent.

Federal expenditures for fiscal 1969 are currently projected to total 5 per cent above fiscal 1968. This is above the level of spending proposed in the Budget message of last January. Increased spending for programs exempt from expenditure limitations is expected to more than offset the $\$ 6$ billion cut required in other areas.

The expansionary fiscal actions necessitated by the Vietnam engagement and the stimulus of monetary expansion prior to mid-year are still influencing the economy. The move toward fiscal restraint has been more than offset in its early stages by the continuing effects of earlier stimulative actions. As the earlier actions run their course, the restrictive pressure of current fiscal actions on the economy should begin to take effect, assuming, of course, that such effects are not more than offset by expansionary monetary actions.

The effect of the current tax program will be reinforced by other legislation scheduled to take effect in late 1968 and early 1969 . The social security tax base has been increased from $\$ 6,600$ to $\$ 7,800$, effective last January. Persons who previously made no further contributions once their income reached $\$ 6,600$, now must pay taxes on an additional $\$ 1,200$.

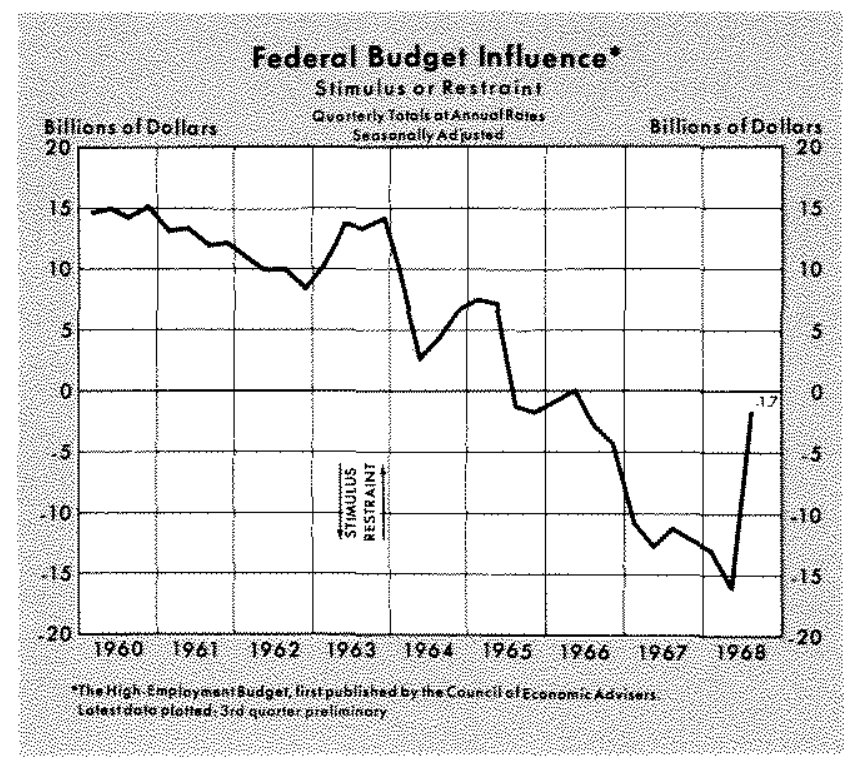

Since the incomes of most individuals do not reach $\$ 6,600$ until after mid-year, a large part of the extra tax is being withheld in the second half of 1968 . Social security tax rates are also scheduled to increase on January 1 of next year, withdrawing an estimated $\$ 1.5$ billion from consumer income in 1969.

The net impract of these fiscal actions is reflected in the high-employment budget. After averaging a $\$ 13$ billion deficit from mid-1967 to mid-1968, the highemployment budget moved to a $\$ 2$ billion deficit in the third quarter. Given the expected course of the Government's program for fiscal 1969, the high-employment budget is expected to be in surplus by $\$ 3$ billion in the first half of calendar 1969.

\section{Monetary Developments}

The rate of monetary expansion is an important determinant of the ultimate success of the fiscal program in dampening inflationary pressures. Since July, monetary indicators have shown divergent patterns (See Table 1I). Growth of member bank re-

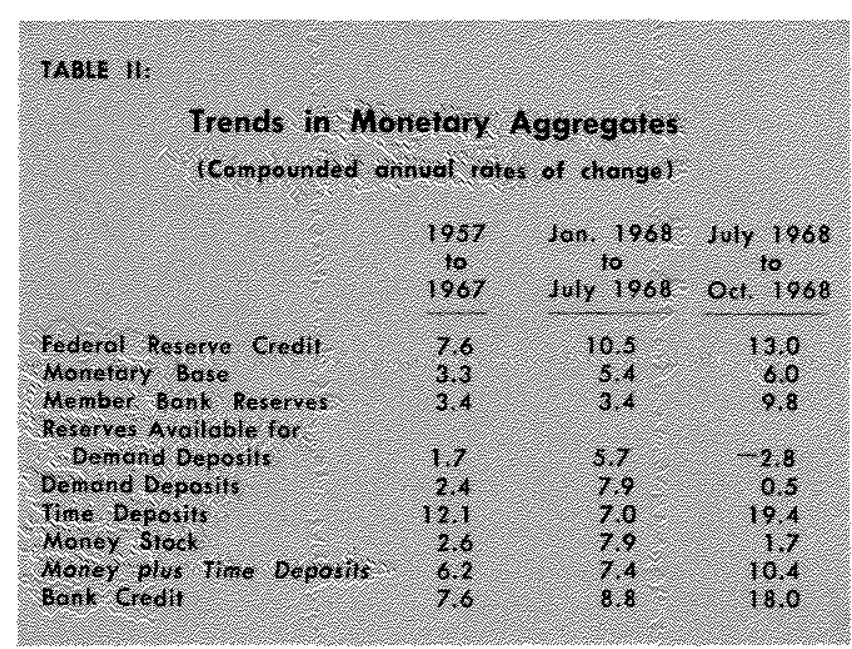

serves, time deposits, money plus time deposits, and bank credit has accelerated. The monetary base and Federal Reserve credit have continued to expand at about the same rates as during the previous six months. Expansion of private demand deposits and the money stock has slowed considerably. In judging which of these measures may best indicate the current monetary influence on total demand, it is necessary to analyze the determinants of the trend growth of these magnitudes.

The major key to the recent diverse monetary trends has been the behavior of market interest rates. Short-term market interest rates began to fall in late May and since mid-year have remained low relative to legal ceiling rates permitted on time deposits. As a result, banks have been able to again attract funds 


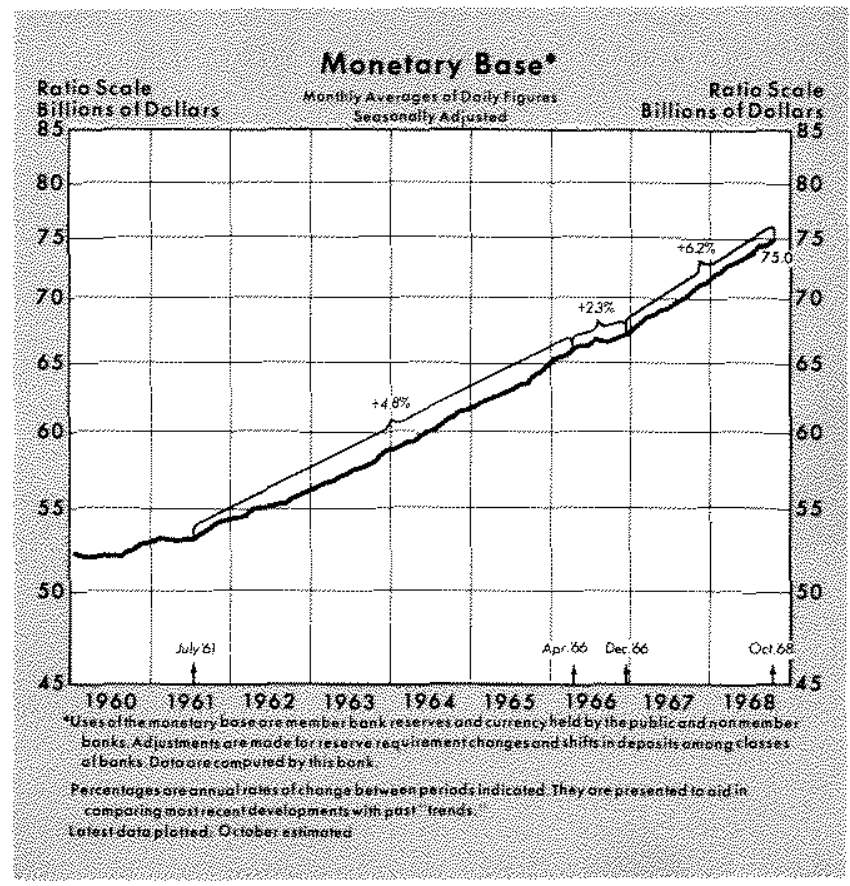

in competition with other market instruments since mid-year. Time deposits have grown at a 19 per cent annual rate since July compared to a 7 per cent rate in the previous six months. The rapid increase of time deposits has resulted in an accelerated growth of bank credit and of money plus time deposits. The expansion of time deposits was largely a diversion of flows of funds from one channel to another and did not necessarily indicate an increase in either total liquid instruments or in total bank and nonbank credit.

The decelerated growth of money since July, measured by private demand deposits plus currency in the hands of the public, may be accounted for in large part by the absorption of reserves and monetary base by the accelerated growth of time deposits. In addition, Government deposits at commercial banks have increased since July. Over the long run, however, the trend growth of money is largely determined by the monetary base, which has continued to grow rapidly in recent months. The base increased at a 6 per cent annual rate in the past three months, compared to a 5.4 per cent rate in the previous six months.
To the extent that growth of the money stock has slowed, monetary influence has probably been less stimulative in the last three months than during the preceding six and eighteen-month periods. Since monetary developments are generally expected to affect total spending with some lag, it should not be expected that the deceleration of monetary expansion would, as yet, have had a restraining influence on total demand and inflation. Further, the effect of the restraint is likely to be moderate and short-lived unless either the growth rate of the monetary base soon slows, or the unusually rapid growth of time deposits continues.

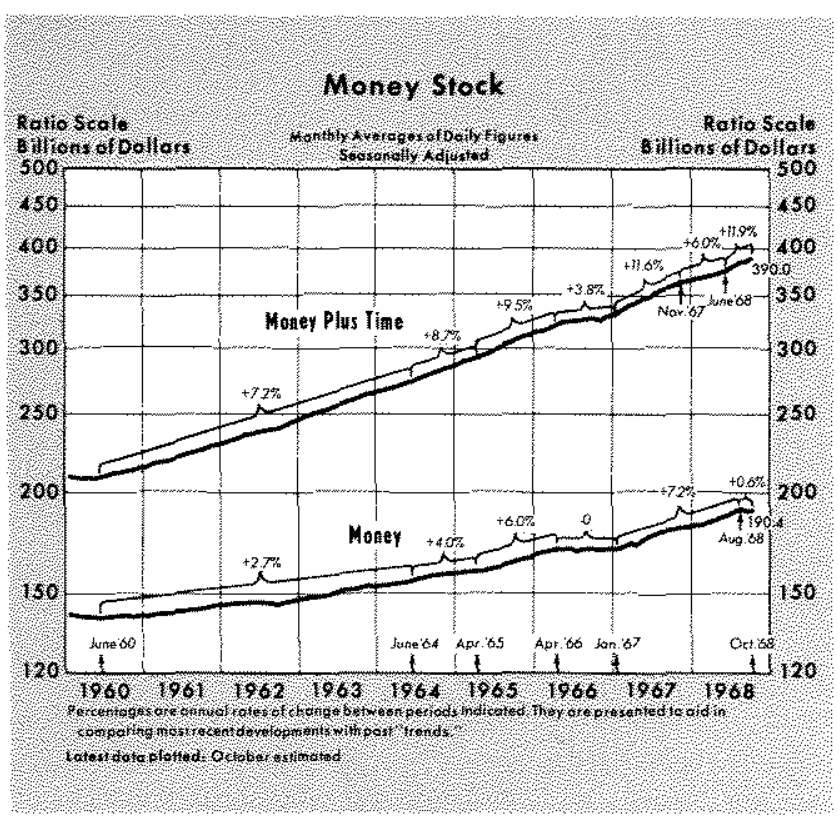

\section{Summary}

Inflationary pressures continued to be strong in the third quarter, as growth of total and final demand remained rapid. While the program of fiscal restraint did not immediately dampen the advance of spending, some degree of moderation may result from this source late this year and early in 1969 . If the less expansionary fiscal situation is accompanied by continuation of the current reduced rate of monetary expansion, growth of final spending and total demand should soon begin to slow. 